\title{
Fuel Efficiency Improvement of Rule-based Algorithm for P0 Mild Hybrid Electric Vehicle
}

\author{
In-Gyu Jang ${ }^{1}$, Sung-Ho Hwang ${ }^{1}$ \\ ${ }^{1}$ School of Mechanical Engineering/Sungkyunkwan University \\ 16419, Suwon, Korea \\ neoera78@gmail.com; hsh0818@skku.edu
}

\begin{abstract}
In this paper, the rule-based control algorithm for 48V Mild Hybrid Electric Vehicle (mHEV) for improving fuel economy was proposed. Control modes are composed of Idle-Stop-and-Go (ISG), Alternating, Regenerative braking, and Boosting. State Machine determines each control mode. For comparison of the fuel economy improvement, the vehicle tests on the vehicle dynamometer were conducted. The test results of the proposed algorithm were compared with the vehicle's fuel economy with ISG as a baseline. As a result, the proposed algorithm improves the fuel economy by $4.5 \%$ in the WLTC cycle.
\end{abstract}

Keywords: 48V, Hybrid Electric Vehicle, Power Management System, Fuel Efficiency Improvement

\section{Introduction}

Unlike a conventional $42 \mathrm{~V}$ system, a $48 \mathrm{~V}$ system is a dual Powernet system that maintains an existing $12 \mathrm{~V}$ power system while adding a $48 \mathrm{~V}$ voltage system [1]. The vehicle's voltage system is divided into low and high voltages based on $60 \mathrm{~V}$ [2]. The $48 \mathrm{~V}$ voltage system can reduce the electrical safety design costs required by high voltage system above 60V [3]. Furthermore, since most of the existing $12 \mathrm{~V}$ power systems can be maintained, development costs can be reduced compared to high voltage HEVs.

Various studies have been reported on improving fuel efficiency for 48V mHEV vehicles [4-5]. Sohn et al. established a strategy to maintain battery charge using the Hamilton-Bellman theory and compared its effectiveness with Dynamic Programming (DP) [4]. Wang et al. proposed an algorithm of Equivalent Consumption Minimizing Strategy (ECMS) considering battery State-Of-Charge (SOC) and evaluated its performance by comparing with DP analysis results through simulation [5]. Studies on fuel economy analysis by the system structure have also been conducted [6-8]. Depending on the position of the $48 \mathrm{~V}$ motor, the HEV can be classified as from P0 to P4. Moreover, an analysis of the fuel economy effect through simulation was conducted [6]. Impacts of powertrain architecture regarding the vehicle's acceleration performance and fuel economy were reported [7-8]. In addition, Sim et al. present a clutch control method for improving fuel efficiency for systems using P0 and P2 simultaneously [9].

This paper presents a rule-based algorithm for fuel economy improvement in the P0 type mHEV system and evaluates fuel economy improvement effects through vehicle tests on a vehicle dynamometer. In section2, P0 type $\mathrm{mHEV}$ system is configured. Section3 proposes a control algorithm to improve fuel economy for P0 type mHEV. Section4 discusses the vehicle test results. Finally, Section5 summarizes the paper and makes conclusions.

\section{System Configuration}

The target system in this paper is $\mathrm{P} 0$ type mHEV with a $48 \mathrm{~V}$ power system. The $48 \mathrm{~V}$ P0 type mHEV replaces the existing $12 \mathrm{~V}$ generator with the $48 \mathrm{~V}$ Belt-driven Starter Generator (BSG). In addition, in comparison to conventional 12V Internal Combustion Engines, the following systems as shown in table 1 are added.

- Wound Rotor type Synchronous Motor (WRSM) BSG for motoring and generating in 48V

- 48V Li-Ion Battery

- $12 \mathrm{~V}-48 \mathrm{~V}$ DC-DC Converter for supplying energy to $12 \mathrm{~V}$ load 
- Hybrid Control Unit (HCU) for controlling the mHEV functions

Figure 1 shows the overall system configuration. The additional systems, including BSG, DC-DC Converter, and $48 \mathrm{~V}$ battery, operate on a 48V Powernet. For the mHEV functionality, the Engine Management System (EMS) and the brake system represented by ABS/ESC must have additional functionalities for cooperative control.

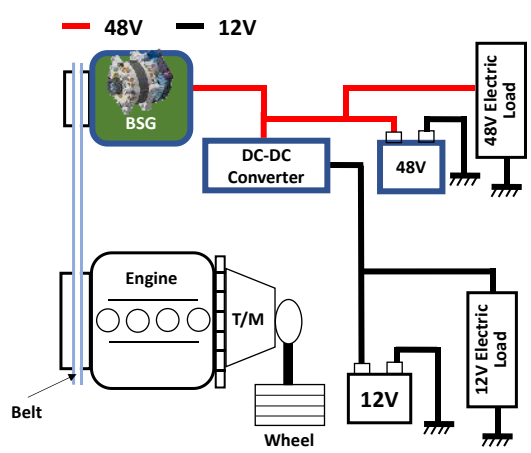

Fig. 1: Configuration of 48V mHEV System.

Table 1: System Specification.

\begin{tabular}{llll}
\hline Sub-system & Feature & Unit & Specification \\
\hline BSG & Operating Voltage & $\mathrm{V}$ & $36 \sim 60$ \\
& Peak.Power & $\mathrm{kW}$ & 10 \\
Battery & Peak.Torque & $\mathrm{Nm}$ & 50 \\
DC-DC Converter & Capacity & $\mathrm{Ah}$ & 8.3 \\
Vehicle & Peak.Power & $\mathrm{kW}$ & 2 \\
& Test Weight & $\mathrm{kg}$ & 1,700 \\
& Engine & - & Diesel 1.7 \\
& Transmission & - & DCT \\
\hline
\end{tabular}

\section{3. mHEV Control Algorithm}

This section describes the mHEV control strategy. The mHEV functionalities for improving fuel economy and their power-flow are as shown in figure 2 (a). mHEV functionalities include engine cranking for ISG, engine boosting for load reduction, alternating for charging the $48 \mathrm{~V}$ battery, and regenerative braking for braking energy recuperation.

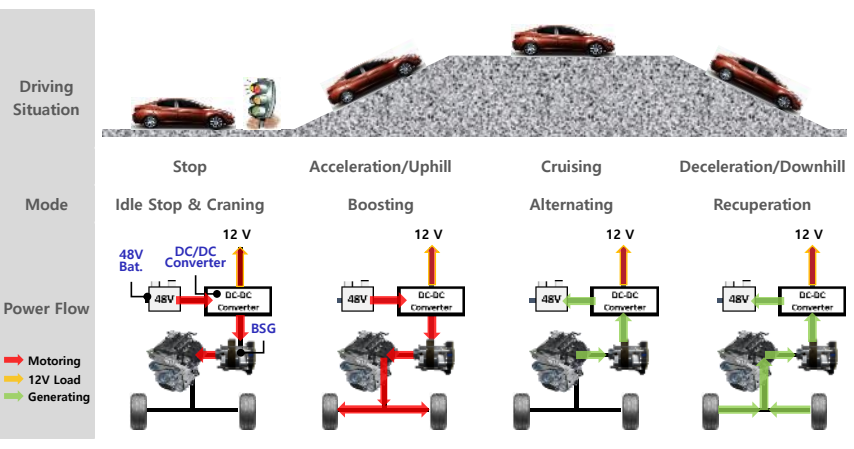

(a) Funstions and Powerflow

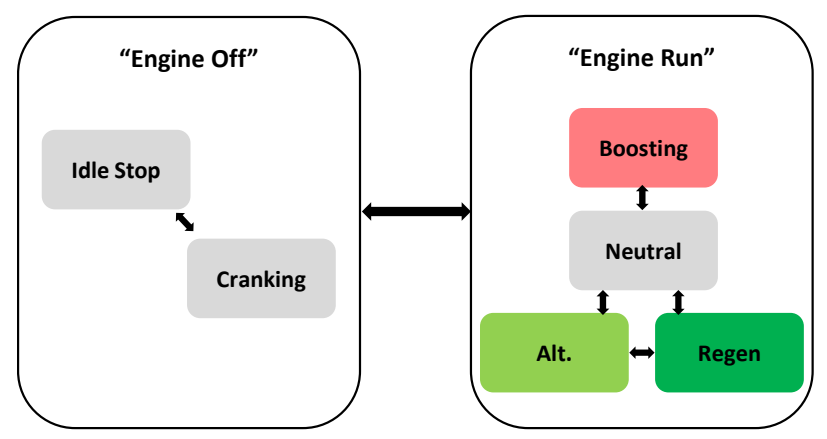

(b) Operating Mode State Machine

Fig. 2: $48 \mathrm{~V}$ mHEV. 
Figure 2 (b) shows the state transition diagram for each function, and table 2 shows the transition conditions. The ISG has the highest priority, and alternating, regenerative braking, and boosting are configured to be determined by the engine operating state. Boosting power distributes the driver's power request using the result of DP(Dynamic Programming).

Table 2: True/False Table for Mode Transition.

\begin{tabular}{l|l|c|c|c|c|c|c}
\hline Case & 1 & 2 & 3 & 4 & 5 & 6 \\
\hline \multirow{5}{*}{ Situation } & Alternating & $\mathrm{T}$ & - & - & - & - & $\mathrm{F}$ \\
\cline { 2 - 8 } & Regenerative braking & $\mathrm{F}$ & $\mathrm{T}$ & $\mathrm{F}$ & - & - & $\mathrm{F}$ \\
\cline { 2 - 8 } & Boosting & $\mathrm{F}$ & - & $\mathrm{T}$ & - & - & $\mathrm{F}$ \\
\cline { 2 - 8 } & Idle Stop & $\mathrm{F}$ & $\mathrm{F}$ & $\mathrm{F}$ & $\mathrm{T}$ & - & $\mathrm{F}$ \\
\cline { 2 - 8 } & Cranking & $\mathrm{F}$ & $\mathrm{F}$ & $\mathrm{F}$ & $\mathrm{F}$ & $\mathrm{T}$ & $\mathrm{F}$ \\
\hline \multirow{3}{*}{ Decision } & Hybrid Mode & Alt. & Regen. & Boost-ing & Stop & Crank-ing & Neutral \\
& & $(3)$ & $(4)$ & $(5)$ & $(8)$ & $(2)$ \\
\cline { 2 - 8 } & Fuel-cut Request & $\mathrm{X}$ & $\mathrm{O}$ & $\mathrm{X}$ & $\mathrm{O}$ & $\mathrm{X}$ & $\mathrm{X}$ \\
\hline
\end{tabular}

\section{Test Results}

The proposed control algorithm was evaluated by the Worldwide harmonized Light-duty vehicle Test Cycle (WLTC) [10]. For comparison of fuel economy improvement, the vehicle equipped with ISG functionality is used. The ISG used a typical enhanced starter motor for engine cranking. Figure 3 shows the test results. In conclusion as shown in table 3 , the proposed control algorithm improved $4.5 \%$ in fuel economy compared to ISG.

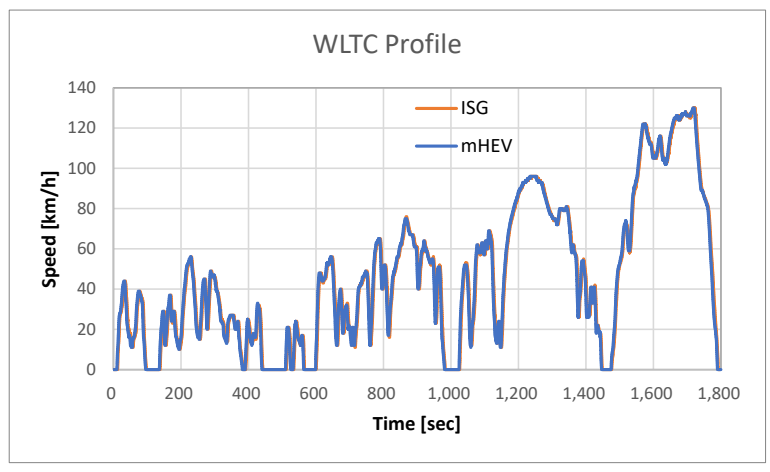

(a) Speed profile

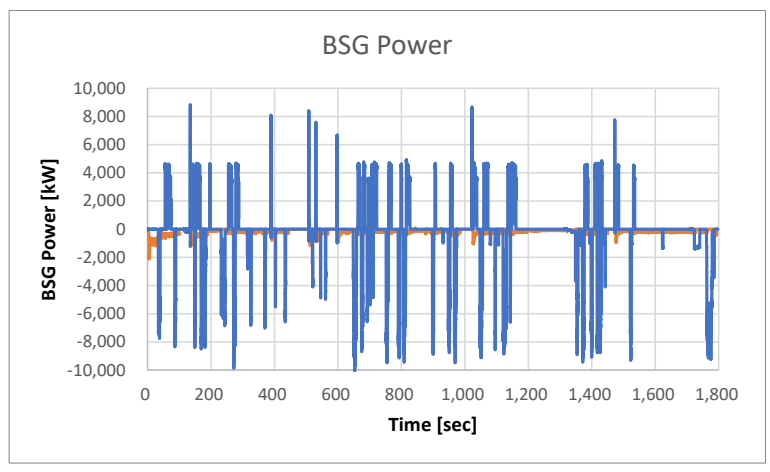

(c) BSG Power

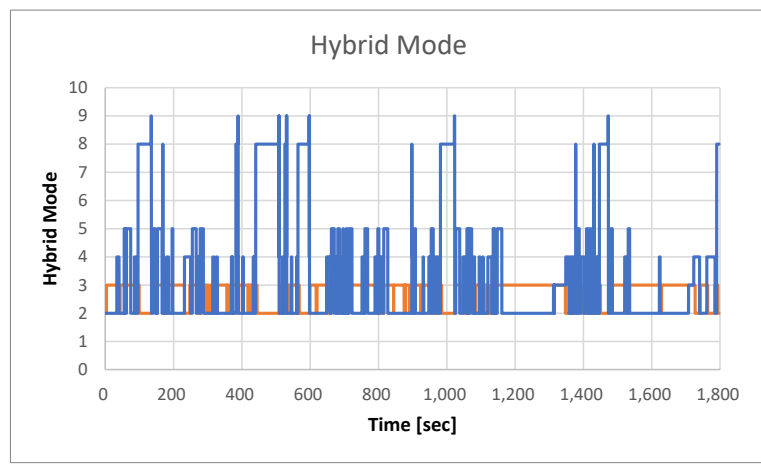

(b) Hybrid Mode

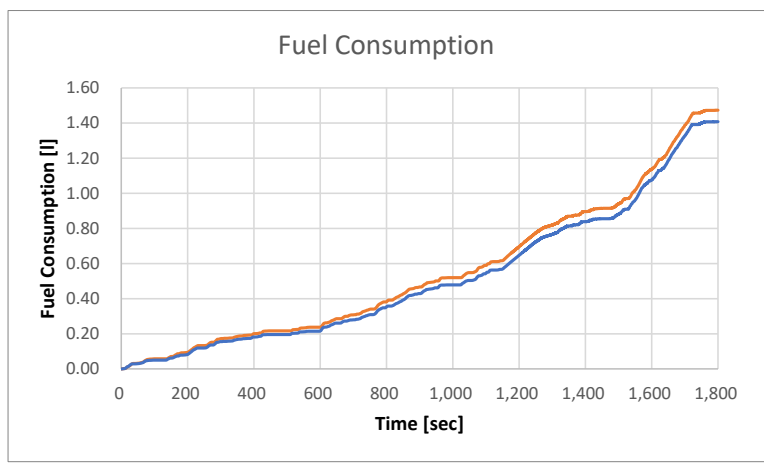

(d) Cumulative Fuel Consumption

Fig. 3: Comparison of test results; ISG vs. mHEV. 
Table 3: Comparison of test results; ISG vs. mHEV

\begin{tabular}{lcrr}
\hline & Unit & Case1. ISG & Case2. mHEV \\
\hline Initial Engine Temperature & ${ }^{\circ} \mathrm{C}$ & 25.5 & 25.5 \\
Initial SOC & $\%$ & 48.5 & 49.5 \\
Final SOC & $\%$ & 48.3 & 48.2 \\
dSOC & $\%$ & -0.2 & -1.3 \\
Cumulative Fuel Consumption & 1 & 1.4731 & 1.4076 \\
Fuel Economy & $\mathrm{km} / 1$ & 15.7 & 16.4 \\
Improvement & $\%$ & - & 4.5 \\
\hline
\end{tabular}

\section{Conclusion}

In this paper, the control algorithm to improve the fuel economy of $48 \mathrm{~V}$ P0 type mHEV has been proposed and evaluated by vehicle tests. The test results show that the proposed control algorithm improves $4.5 \%$ in fuel economy in comparison to the ISG vehicle. Therefore, for automotive makers, 48V P0 type mHEV with the proposed control algorithm is expected to be one of the measures to comply with the environmental regulations.

\section{Acknowledgements}

This research was supported by the MSIT (Ministry of Science and ICT), Korea, under the ITRC (Information Technology Research Center) support program (IITP-2021-2018-0-01426) supervised by the IITP (Institute for Information \& Communications Technology Planning \& Evaluation). This research was supported by the program for fostering next-generation researchers in engineering of National Research Foundation of Korea(NRF) funded by the Ministry of Science and ICT (2017H1D8A2031628)

\section{References}

[1] Ottmar Sirch, "The New Voltage Level 48Volt In Vehicles," 6th Annual Conference Steering Systems, 2012

[2] Regulation No 100 of the Economic Commission for Europe of the United Nations (UNECE) - Uniform provisions concerning the approval of vehicles with regard to specific requirements for the electric power train [2015/505]

[3] IEC 60038:2009, "IEC Standard Voltages", 2009

[4] J. Shon, M. Sunwoo, K. Min, J. Shin, and M. Han, "Power Management Strategy for the 48 V Mild Hybrid Electric Vehicle Based on the Charge-Sustaining Control," Int. J. of Automotive Technology, 20(2019), 37-49

[5] Y. Wang and Z. Huang, "Optimization-Based Energy Management Strategy for a 48-V Mild Parallel Hybrid Electric Power System," J. of Energy Resources Technology, 142(5): 052002, 2020

[6] R. Bao, V. Avila, and J. Baxter, "Effect of 48 V Mild Hybrid System Layout on Powertrain System Efficiency and Its Potential of Fuel Economy Improvement," SAE Technical Paper 2017-01-1175, 2017

[7] J. Rossi and C. Cavallino, "Modular P2-P3 Dedicated Hybrid Transmission for 48V and HV applications," 2017 International Conference of Electrical and Electronic Technologies for Automotive, Torino, 2017, 1-4

[8] A. Kumaran, A. Emran, R. S. Rajan, V. Sharma, G. Sadekar, M. Laermann, M. Kotter, H. Lahey, and T. Korfer, "Affordable hybrid topology for PV and LDV's in prospering India: Case study of 48V (P)HEV system benefits," 2017 IEEE Transportation Electrification Conference (ITEC-India), Pune, 2017, 1-6

[9] K. Sim, S. Oh, C. Namkoong, J. Lee, K. Han, and S. Hwang, "Control strategy for clutch engagement during mode change of plug-in hybrid electric vehicle," Int. J. of Automotive Technology, 18(2017), 901-909

[10] M. Tutuianu, P. Bonnel, B. Ciuffo, T. Haniu, N. Ichikawa, A. Marotta, J. Pavlovic, and H. Steven, "Development of the World-wide harmonized Light duty Test Cycle (WLTC) and a possible pathway for its introduction in the European legislation," Transportation Research Part D: Transport and Environment, 40(2015), 61-75 